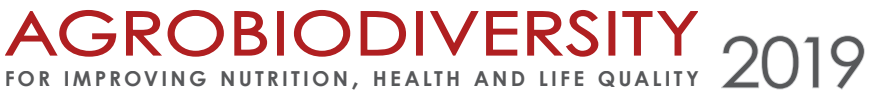

$\odot$

\section{PROMISING PLUM CULTIVARS AND SELECTION FROM THE UKRAINIAN BREEDING PROGRAM}

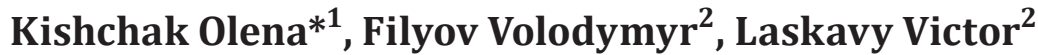 \\ ${ }^{1}$ Institute of Horticulture National Academy of Agrarian Sciences of Ukraine, Kyiv, Ukraine \\ ${ }^{2}$ L.P. Symyrenko Station of Pomology Institute of Horticulture National Academy of Agrarian Sciences \\ of Ukraine, Mliiv, Ukraine
}

Received: 25. 3. 2019 Revised: 27. 11. $2019 \quad$ Published: 30. 11. 2019

The authors present the research results of new plum cultivars and promising selections (Prunus domestica L.), bred at the L.P. Symyrenko research pomology station of the Institute of Horticulture NAAS of Ukraine, under the conditions of the Ukrainian Western Forest-Steppe in order to select the most promising in the relation of economic-valuable traits. Field, laboratory, comparative research methods have been applied as well as statistical ones. The cultivars with compact crown habit and high unit yield capacity, in particular Oda, Nenka, selection № 8087 (Aria), which crown volume have never exceed $20 \mathrm{~m}^{3}$ and the unit productivity was $2.0-2.5 \mathrm{~kg} / \mathrm{m}^{3}$, were distinguished. In addition to these, high yield capacity per area unit had such varieties as Originalna, Prestige and selection № 8121 (Yantarna Mlyivska). It was established that their fruits are characterized by a high average mass (41.4-58.3 g), high flavor properties (8.4-8.5 points) and can be used in commercial orchards of Ukraine. Thus, among the studied varieties there were determined the best according to the complex of valuable economic features: in early ripening group - Nenka and Oda, the middle ripening - elite selections No. 8087 (Aria), No. 12456 (Dobra), No. 8121 (Yantarna Mlyievska), and the late-ripening ones Originalna and Prestige, which can be widely used in commercial orchards of Ukraine for significantly increase of yields and profitability.

Keywords: Prunus domestica, cultivars, fruits, growth, yield

\section{Вступ}

Слива $є$ цінною плодовою породою завдяки унікальним дієтичним та технологічним властивостям ії плодів.

В Україні на кінець 2017 року загальна площа під садами цієї культури становила 20,4 тис. га. Частка сливи в структурі кісточкових $€$ досить високою - 29,6 \%, займаючи друге місце після вишні (31,1%). Серед провідних світових виробників плодів сливи Україна знаходиться на дванадцятому місці з обсягом у 2017 р. -

\footnotetext{
*Corresponding author: Olena Kishchak, Institute of Horticulture of National Academy of Agrarian Sciences of Ukraine, Kyiv, Sadova 23, 03027 Kyiv, Ukraine $\triangle$ cherry0308@ukr.net
} 
200,5 тис. т і врожайністю 10,9 т/га, що становить 1,5 \% від загального обсягу світового виробництва (Derzhavna Sluzhba Statystyky Ukrayiny, 2019).

Визначальним фактором у ефективному виробництві плодової продукції належить сорту. Його частка в підвищенні врожайності плодових культур оцінюється в 40-70 \% (Savieliev, 2003). При цьому залучення у виробництво кращих нових сортів не потребує додаткових капітальних вкладень (Shestopal', 2006).

Кліматичні умови України є оптимальними для успішного промислового вирощування сливи, водночас їі прибуткове виробництво можливе лише за умов використання відповідних сортів. Основні площі промислових садів в нашій державі представлені такими сортами як Ганна Шпет та Стенлей, питома вага яких у виробництві садивного матеріалу за 2015 рік становила відповідно 14,9 та 75,8 \% (Bazilevs'ka, 2015).

Тенденції на світовому ринку свідчать про те, що зростає попит на крупноплідні сорти сливи ранніх та пізніх строків достигання масою не менше 45-50 г високих смакових якостей, які можуть реалізовуватися у свіжому вигляді за найвищою ціною. Найбільш популярними в Європі насьогодні є Президент, Стенлей, Чачакська найболіа, також набувають поширення стійкі до іржі та вірусу шарки сорти Топхіт, Топенд плюс та ін. (Rozpara, 2004; Botu, 2012; Bolat, 2017).

Водночас, актуальним залишається добір сортів і для переробної промисловості, яким би були властиві стабільна врожайність і легке відокремлювання невеликої кісточки від м'якоті плоду.

Крім того, у зв'язку із зміною клімату основною вимогою до сорту є висока стійкість до несприятливих абіотичних та біотичних факторів довкілля.

Отже, одним із пріоритетних завдань в селекції сливи є створення високопродуктивних адаптивних до умов вирощування крупноплідних сортів з високою товарною якістю плодів.

\section{Матеріали та методика}

\section{Місце проведення досліджень}

Досліди проведено протягом 2016-2018 рр. на Дослідній станції помології ім. Л.П. Симиренка (м. Мліїв, Черкаська обл.), яка входить до структури Інституту садівництва Національної академії аграрних наук України (далі - IC НАAН), і на сьогодні $є$ провідною установою зі створення сортів сливи в Україні.

\section{Мета досліджень}

полягала у виділенні сортів, які б відповідали вимогам сучасного садівництва і могли значно покращити районований сортимент. 


\section{Об'єкти досліджень}

Вивчалися 14 сортів та 9 елітних форм сливи різних строків достигання, зокрема: ранньостиглі сорти і форми (III декада липня - I декада серпня) - Ненька (контроль), Ода і Герман; середньостиглі (II-III декада серпня) - Ренклод Карбишева (контроль), № 12516, № 7756 (Ізюминка), № 8087 (Арія), № 9605, № 9996 (Юна), № 12456 (Добра), Заманчива, Чачакська краща і Янтарна Мліївська; пізньостиглі (I-II декада вересня) - Стенлей (контроль), № 7794 (Розважлива), №8110 (Фантазія), № 8164 (Престиж), №8143, Рекорд, Топхіт, Блюфрі, Президент і Штутгарт.

\section{Методика проведення досліджень}

Зазначені сорти і форми щеплено на сіянцях аличі та висаджено у 2000 р. за схемою $6 \times 4$ м. Кількість облікових дерев на ділянці - 10, повторень - 3, розміщення варіантів рендомізоване.Комплекснуоцінку сортівтагібридівпроводили зазагальноприйнятими методиками (Siedov and Ogolcova, 1999; Metodyka.., 2004).

\section{Результати та обговорення}

При створенні інтенсивних насаджень велике значення має сила росту сортів сливи. Для зручності догляду за такими садами більшу перспективу мають сорти з компактним габітусом крони в поєднанні з слаборослими підщепами, що дозволить більш щільно розміщувати дерева на одиниці площі (Eriomin, 2003; Sobol' and Kolesnyk, $2005)$ та механізувати процес збирання врожаю (Rozpara, 2012). Попередні дослідження в Інституті садівництва НААН показали, що для створення щільних садів придатні сорти Богатирська, Ода, Стенлей та Вереснева (Zavgorodnyaya and Pavlyuk, 1988).

Дослідженнями встановлено істотні відмінності за силою росту та габітусом крони дерев сливи. Найбільшою висотою (більше 4 м) та об'ємом крони (понад 25 м $^{3}$ ) відзначалися сорти Рекорд, Блюфрі, Президент та Ренклод Карбишева. Виділено слаборослі сорти Ода і Ненька, у яких висота дерев не перевищує 3,0 м, а об'єм 15 м $^{3}$, що дає можливість використовувати їх в садах із щільним розміщенням дерев.

Компактним габітусом крони також відрізнялися дерева елітних форм № 7756 (Ізюминка), № 8087 (Арія) та № 9605, у яких об’єм крони не перевищував 20 м³. Дерева всіх сортів за роки досліджень мали добрий загальний стан та високу зимостійкість.

Найбільш раннє достигання плодів відмічається у сортів Ненька (III декада липня) та Ода (I декада серпня), яким у районованому сортименті за строками достигання і слаборослістю не має аналогів.

До групи середньостиглих віднесено Заманчиву, Трудівницю Млієва, Кантату та елітні форми № 8121 (Янтарна Мліївська), № 12456 (Добра), № 7756 (Ізюминка), № 9996 (Юна), № 8087 (Арія). Їх плоди достигають у другій декаді серпня. Пізнім достиганням плодів (вересень) на рівні контрольного сорту Стенлей відзначається Волошка, Оригінальна, Окраса саду та форми № 8164 (Престиж), № 8110 (Фантазія), № 7794 (Розважлива). 
Найголовнішим критерієм господарської оцінки сортів сливи є їх врожайність. За цим показником виділилися з ранньостиглих сортів Ненька і Ода (14,6-15,7 т/га), середньостиглих - елітна форма № 8121 (Янтарна Мліївська) - 16,5 т/га та з групи пізніх - Оригінальна і № 12456 (Добра) - (16,7 т/га) та № 8124 (Престиж) - 16,0 т/га. Оцінку основних сортів та елітних форм наведено в Таблиці 1.

Таблиця 1 Основні господарсько-біологічні показники сортів та елітних форм сливи (середнє за 2016-2018 pp.)

Table 1 Basic economic and biological indices of varieties and elites forms of plum (average for 2016-2018)

\begin{tabular}{|c|c|c|c|c|c|}
\hline \multirow[t]{2}{*}{ Сорт, форма } & \multicolumn{2}{|c|}{ Урожайність } & \multicolumn{2}{|c|}{ Маса плоду (г) } & \multirow{2}{*}{$\begin{array}{l}\text { Дегустаційна } \\
\text { оцінка (бал) }\end{array}$} \\
\hline & т/га & $\kappa г / \mathbf{M}^{3}$ & середня & максимальна & \\
\hline \multicolumn{6}{|c|}{ Ранньостиглі } \\
\hline Ненька (к) & 14,6 & 2,4 & 49,6 & 63,6 & 8,5 \\
\hline Ода & 15,7 & 2,5 & 41,4 & 43,9 & 8,4 \\
\hline \multicolumn{6}{|c|}{ Середньостиглі } \\
\hline Ренклод Карбишева (к) & 12,3 & 1,2 & 41,8 & 54,3 & 8,4 \\
\hline № 7756 (Ізюминка) & 10,4 & 1,4 & 37,2 & 40,5 & 8,4 \\
\hline № 8087 (Арія) & 13,8 & 2,0 & 43,2 & 51,8 & 8,4 \\
\hline № 12456 (Добра) & 16,7 & 1,5 & 47,2 & 57,1 & 8,5 \\
\hline № 8121 (Янтарна Мліївська) & 16,5 & 1,9 & 58,3 & 71,5 & 8,0 \\
\hline \multicolumn{6}{|c|}{ Пізньостиглі } \\
\hline Стенлей (к) & 15,4 & 1,7 & 43,9 & 56,1 & 8,3 \\
\hline Волошка & 15,1 & 1,4 & 57,2 & 66,5 & 8,3 \\
\hline Оригінальна & 16,7 & 1,6 & 40,4 & 52,7 & 8,5 \\
\hline № 8115 (Окраса саду) & 14,6 & 1,4 & 62,0 & 75,1 & 8,5 \\
\hline № 8124 (Престиж) & 16,0 & 1,8 & 49,8 & 58,4 & 8,0 \\
\hline № 7794 (Розважлива) & 13,1 & 1,5 & 33,4 & 37,8 & 8,5 \\
\hline № 8110 (Фантазія) & 14,8 & 1,6 & 43,2 & 48,9 & 8,5 \\
\hline HIP $_{05}$ & 1,8 & 0,2 & 4,6 & 6,7 & 0,7 \\
\hline
\end{tabular}

Сорти з високою питомою продуктивністю дають можливість більш ефективно використовувати відведену земельну площу, що підвищує ефективність виробництва плодів сливи. За цим показником з розрахунку на $1 \mathrm{~m}^{3}$ крони виділяються слаборослі сорти Ненька і Ода (2,4-2,5 кг/м³), а також елітні форми № 8087 (Арія) - 2,0, № 8121 (Янтарна Мліївська) - 1,9, № 8124 (Престиж) - 1,8, № 8110 (Фантазія) і Оригінальна $(1,6)$ та контрольний сорт Стенлей $-1,7$ кг/м³.

Величина та смакові властивості плодів $є$ основними показниками при визначенні їх якості. Велику середню масу від 36 до 45 г формують практично всі досліджувані 
сорти за виключенням елітної форми № 7794 (Розважлива), дуже велику (понад 45 г) зафіксовано у Неньки $(49,6$ г), Волошки $(57,2$ г) та елітних форм № $12456(47,2)$, № 8121 (58,3), №8115 (62,0) і № 8124 (49,8 г). У цих сортів та елітних форм середня та максимальна маса плодів була в 1,2-1,4 рази більшою, ніж в контролі.

У плодів усіх сортів, які вивчалися, кісточка добре відділяється від м'якоті, що є важливоювластивістюпри виготовленнісоків,желе, виноматеріалівтависокоякісного чорносливу. Зовнішній вигляд та дегустаційну оцінку проводили за дев'ятибальною шкалою. Найбільш привабливими виявилися плоди сорту Ненька, Оригінальна та елітних форм № 12456, № 8121 та № 8124. Ці ж сорти виділяються за смаковими якостями, вмістом цукрів (9,36-12,1 \%), сухих розчинних речовин $(13,95-16,49 \%)$ й органічних кислот (0,78-0,86 \%). Тому не випадково, що у Державному реєстрі сортів рослин, придатних для поширення в Україні на 2019 рік налічується 14 сортів сливи, з яких 9 - мліївської селекції, які повинні вирішити нагальні питання промислового вирощування сливи (Derzhavnyi Reiestr, 2019).

Наводимо коротку характеристику найбільш перспективних сортів сливи різних сортів достигання Дослідної станції помології ім. Л.П. Симиренка IC HAAH.

Ода (Рисунок 1) - ранньостиглий сорт (I декада серпня), отриманий від штучного запилення сорту Волошка сумішшю пилку сортів Кірке, Артон, Угорка ажанська і Катерина синя. Дерево середньоросле, утворює округлу середньої густоти крону.

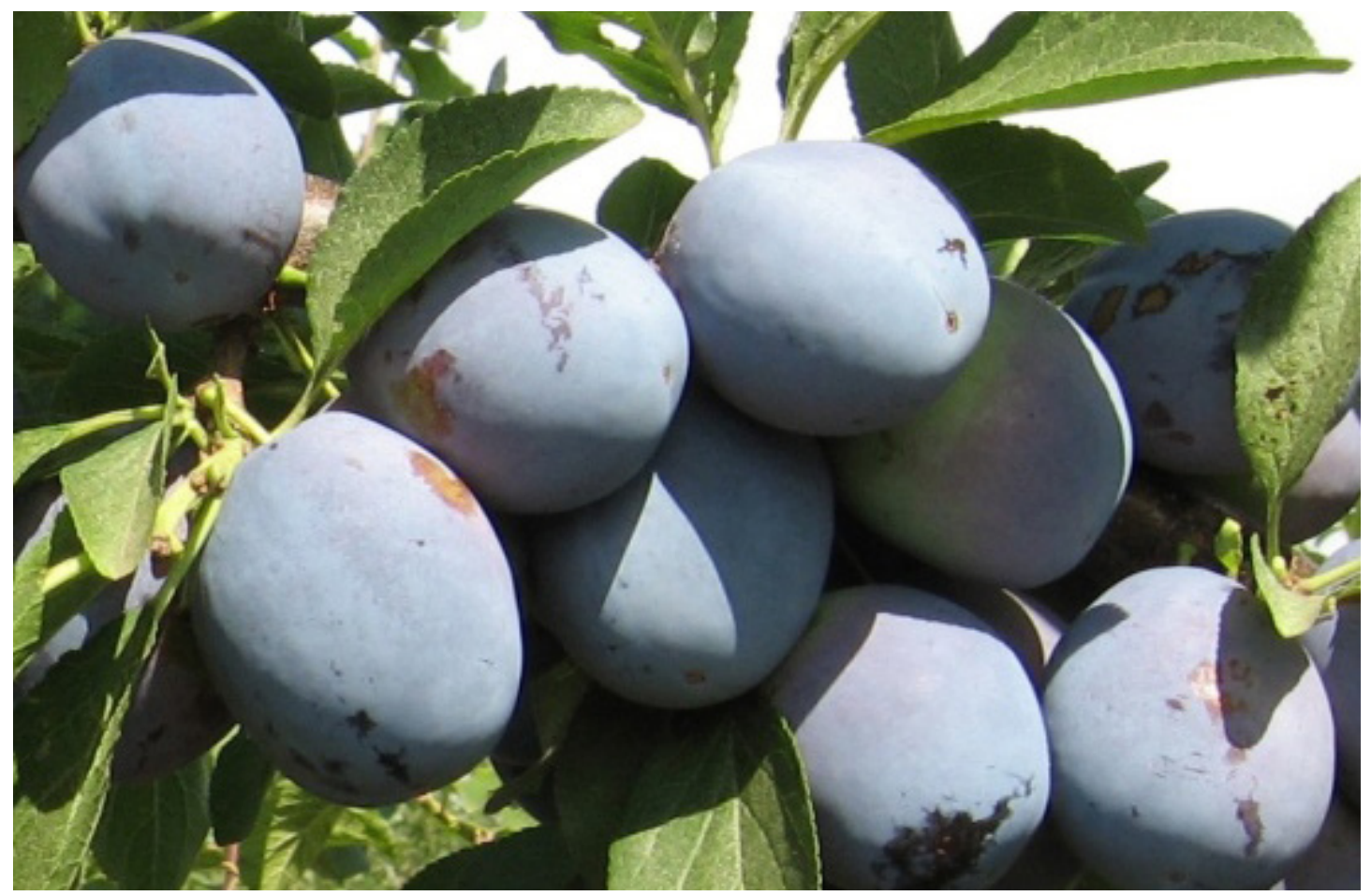

Рисунок 1 Плоди сорту Ода

Figure 1 Fruits of cv. Oda 
Вступає в плодоношення на 3-4 рік після садіння, забезпечуючи врожай 40-45 кг з дерева. Плоди великі, одномірні, овальної форми, кісточка вільна. Середня маса 40-50 г. Основне забарвлення плоду зелене, покривне - фіолетово-буре. Шкірочка середньої щільності з сильним восковим покриттям. М'якуш жовтий, ніжний, соковитий, кисло-солодкого смаку. Плоди містять 17,68 \% сухих речовин, 7,9 - цукру, $0,75 \%$ - органічних кислот.

Добра (Рисунок 2) - середньостиглий сорт (II-III декада серпня), отриманий від запилення гібридної форми № 8143 пилком сорту Персикова. Дерево середньоросле з обернено пірамідальною середньої густоти кроною. Вступає в плодоношення на 3-4 рік після садіння, урожайний (35-40 кг/дер.). Плоди крупні, одномірні, овальної форми. Середня маса 47-57 г. Основне забарвлення плоду жовто-зелене, покривне - від червоно-бурого до темно-синього. Шкірочка середньої щільності з легким восковим нальотом. М'якуш жовто-зелений, щільний, соковитий, хрящуватий, кисло-солодкого смаку. Плоди містять 18,94 \% сухих речовин, 12,60 - цукру, 0,87 \% - органічних кислот.

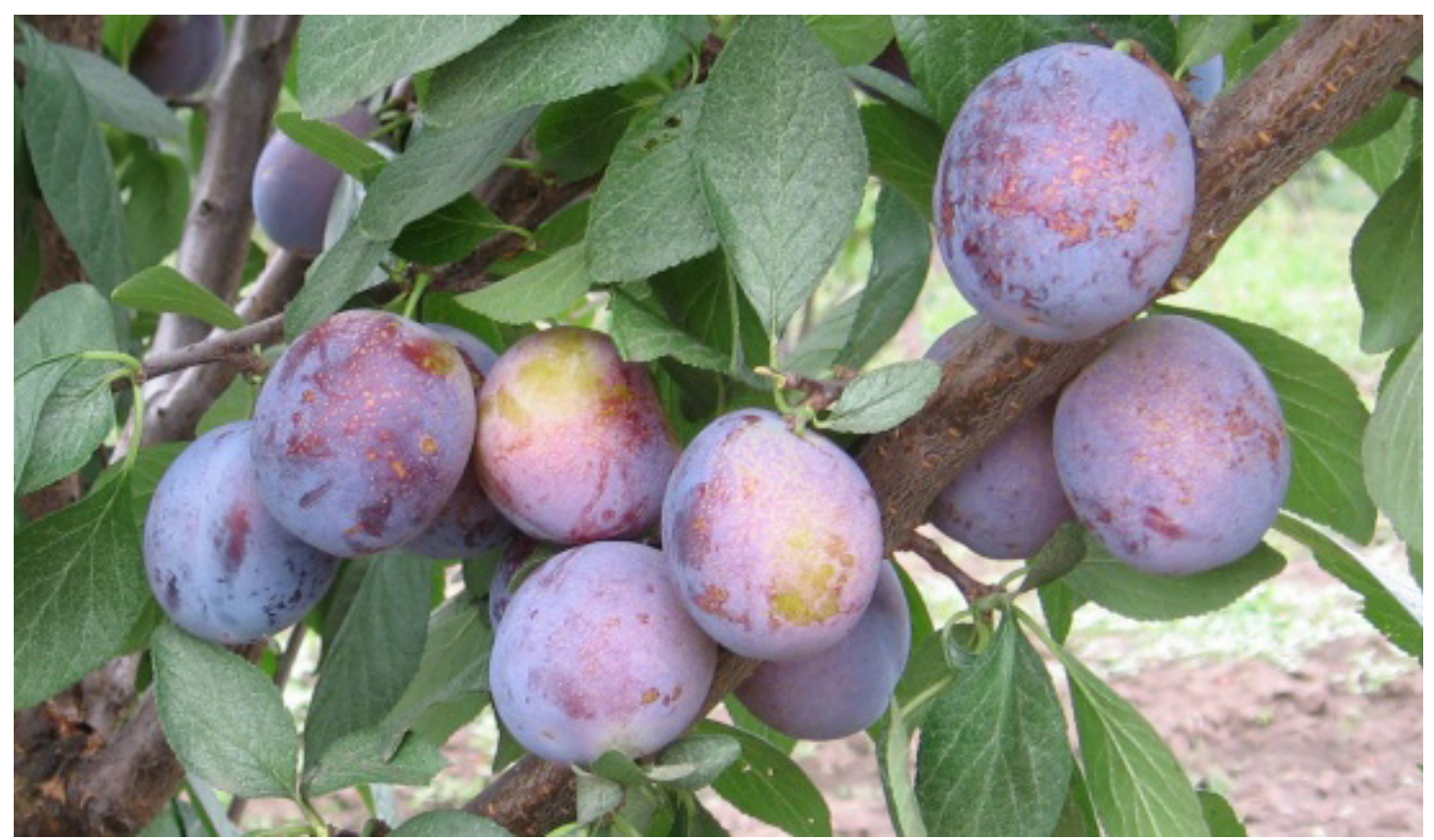

Рисунок 2 Плоди сорту Добра

Figure 2 Fruits of cv. Dobra

Оригінальна (Рисунок 3) - пізньостиглий сорт (III декада серпня - I декада вересня), отриманий шляхом відбору серед сіянців від вільного запилення сорту Волошка. Дерево середньоросле з округлою припіднятою середньої густоти кроною. Вступає в плодоношення на 3-4 рік після садіння, урожайний (40-45 кг/дер.). Плоди великі, одномірні, округлої форми. Середня маса 40-50 г. Шкірочка еластична, середньої щільності з легким восковим покриттям. М'якуш жовтий, щільний, соковитий, 
хрящуватий, кисло-солодкого смаку. Плоди містять 16,90 \% сухих речовин, 9,2 - цукру, $0,77 \%$ - органічних кислот.

Зазначені сорти сливи включено до Державного реєстру сортів рослин, придатних для поширення в Україні та рекомендовано для промислових насаджень у зоні Лісостепу.

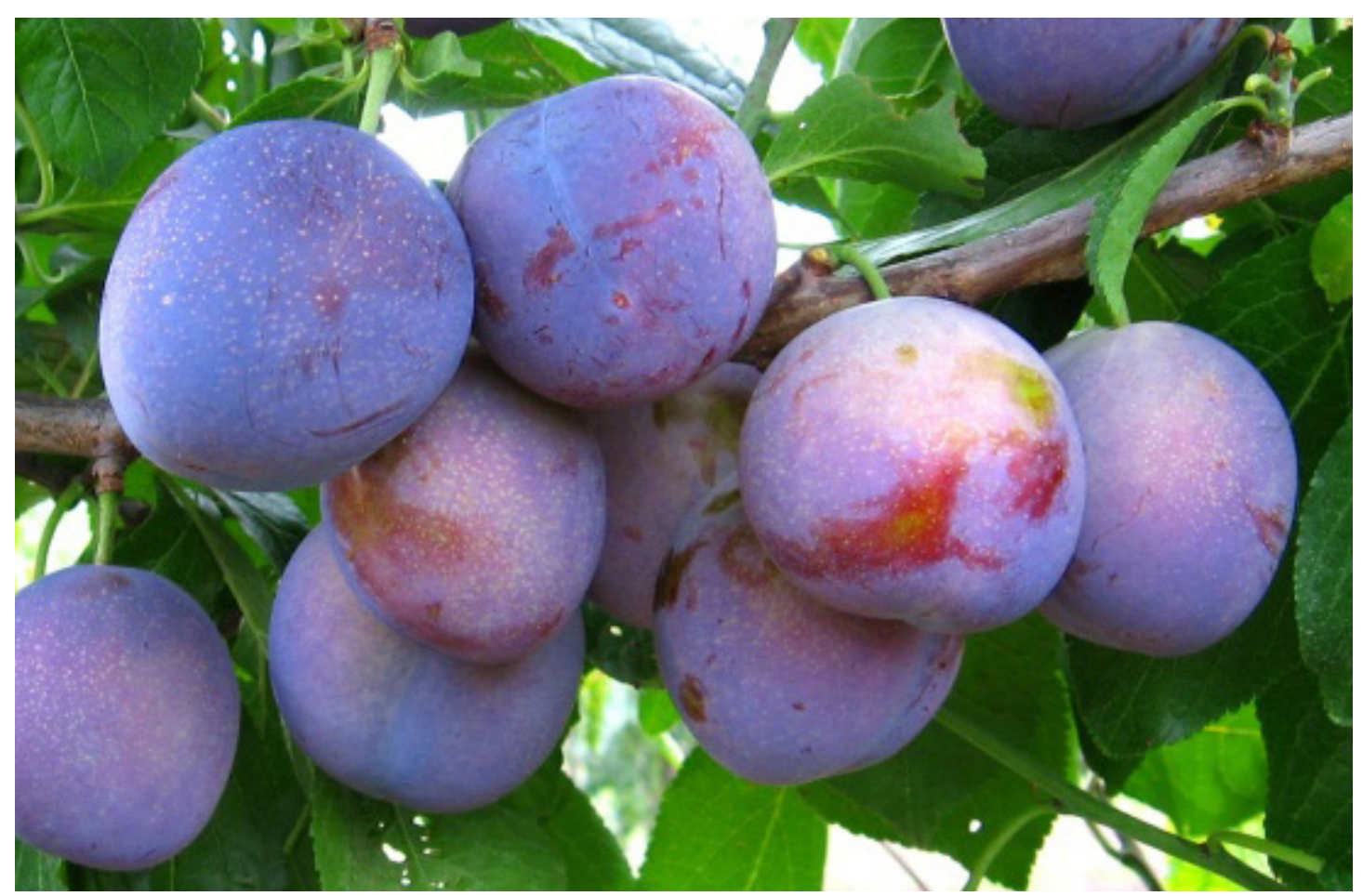

Рисунок 3 Плоди сорту Оригінальна

Figure 3 Fruits of cv. Originalna

\section{Висновки}

Таким чином, за комплексом господарсько-цінних ознак серед сортів, які вивчалися з групи ранньостиглих виділяються Ненька та Ода, середньостиглих елітні форми № 8087 (Арія), №12456 (Добра), № 8121 (Янтарна Мліївська) та пізньостиглих - Оригінальна і № 8124 (Престиж). Використання цих сортів і форм в промислових садах дозволить значно підвищити їх врожайність та прибутковість господарств.

\section{Література}

BAZILEVS'KA, V.M. 2015. Perelik sadivnoho materialu plodovich, yagidnich gorihoplidnich, maloposhirenich kultur, vynogradu ta hmelyu, vyroshchenoho v Ukrayini u 2015 r [Enumeration of the planting stock of the fruit, small fruit, nuciferous, minor crops, grape and hop grown in Ukraine in 2015]. K. : UDPAI. 45 p. [In Ukrainian]. 
Derzhavnyi Reyestr Sortiv Roslyn, Prydatnych Dla Poshyrennia V Ukrayini Na 2019 Rik. 2019. [State register of the cultivars of the plants valuable for the spread in Ukraine for 2019]. Available at: https://sops.gov.ua/reestr-sortiv-roslin

Derzhavna Sluzhba Statystyky Ukrayiny. 2019. Elektronnyi resurs [State Statistics service of Ukraine]. Available at: https://www.ukrstat.gov.ua

ERIOMIN, G.V. 2003. Sliva I alycha [Plum and mirobalan plum]. Kharkiv : Folio, 302 p. [In Russian].

ZAVGORODNYAYA, V.G., PAVLYUK, V.V., 1988. Ranniye sorta slivy dlya Lesostepi Ukrainy. [Early plum varieties for Lisosteppe of Ukraine ]. In Sadivnytstvo, vol. 36, p. 55-57. [In Russian].

Metodyka Derzhavnogo Vyprobuvannia Sortiv Roslyn Na Prydatnist' Do Poshyrennia V Ukrayini. 2005. [Methods of the plants cultivars state testing on the spread in Ukraine]. In Ohorona prav na sorti roslin. Official. Bul. Ch. 2. - K. : Derzhavna sluzhba z ohoroni prav na sorti roslin, p. 161-232. ISBN 978-966-924-038-5. [In Ukrainian].

SAVIELIEV, N.I. 2003. Praktichieskiie riezultaty i pierspiektivy soviershienstvovaniya sortimenta yabloni na gienetichieskoj osnovie [Role of cultivars and new technologies in the intensive horticulture]. In Materialy mezhdunarodnoj nauchno-metodicheskoj konferencii. Rol sortov i novyh tehnologij v intensivnom sadovodstve, Oryol, p. 306-308. ISB №5 - 900-705-23-4. [In Russian].

SIEDOV, E.N., OGOLCOVA, T.P. 1999. Programma i metodika sortoizucheniya plodovych, yagodnych i oriehoplodnyh kultur [Programme and methods of the strain investigation of fruit, small fruit and nuciferous crops]. Oryol : Izd-vo VNIISPK, 608 p. ISBN 5-900705-15-3. [In Russian].

SHESTOPAL', O.M. 2006. Metodika ekonomichnoyi ta enerhetichnoyi ocinky typiv nasadzhen', sortiv, investycij $v$ osnovnij kapital, innovacij ta rezultativ technologichniych doslidzhen' u sadivnyctvi [Methods of the economic and energetical estimation of the types of the orchards, cultivars, investment into the fixed capital, innovations and results of the technological researches in horticulture] Kyiv : Instytut sadivnyctva UAAN, 140 p. [In Ukrainian].

SOBOL', V.A., KOLESNYK, V.A. 2005. Intensyvni nasadzhennya slyvy na nasinnyevykh i klonovykh pidshchepakh v zoni pivnichnoho Lisostepu Ukrayiny [Intense plum orchards on seed and clonal rootstocks in the Northern lisosteppe of Ukraine]. In Sadivnytstvo, vol. 56, p. 90-98. [In Ukrainian].

BOLAT, I., ACAR, I., IKINCI, A. 2017. Plum culture in Turkey. In Acta Horticulturas, vol. 1175, p. 15-18. https://doi.org/10.17660/ActaHortic.2017.1175.4

BOTU, I. 2012. Evolution of plum culture: constrains and perspectives. In Acta Horticulturae, vol. 968, p. 19-24. https://doi.org/10.17660/ActaHortic.2012.968.1

ROZPARA, E. 2004. Nowości odmianowe śliw, wiśni i czereśni. Ogolnopolska konferencia. In Proceedings of the Conference "Nowości w technologii produkcii śliw, wiśni i czereśni. Skierniewice", p. 26-30.

ROZPARA, E. 2012. Plum production and research in Poland. In II EUFRIN Plum and Prune Working Group Meeting on Present Constraints of Plum Growing in Europe, Romania, p. 31-37. ISBN 978-90-66056-75-6 